\title{
InMotion, corps et architecture
}

\section{Haze Kware}

\section{(2) OpenEdition}

Journals

Édition électronique

URL : http://journals.openedition.org/rbnu/1224

DOl : $10.4000 /$ rbnu. 1224

ISSN : 2679-6104

\section{Éditeur}

Bibliothèque nationale et universitaire de Strasbourg

\section{Édition imprimée}

Date de publication : 1 novembre 2016

Pagination : 84-95

ISBN : 9782859230630

ISSN : 2109-2761

\section{Référence électronique}

Haze Kware, «InMotion, corps et architecture », La Revue de la BNU [En ligne], 14 | 2016, mis en ligne le 01 janvier 2020, consulté le 12 décembre 2020. URL : http://journals.openedition.org/rbnu/1224 ; DOl : https://doi.org/10.4000/rbnu. 1224

\section{(C) $10(0$}

La Revue de la BNU est mise à disposition selon les termes de la Licence Creative Commons Attribution - Pas d'Utilisation Commerciale - Partage dans les Mêmes Conditions 4.0 International. 


\section{InMotion, corps et architecture}

Haze Kware (de son vrai nom Andriamampandry Andriantsoa) s'est d'abord consacré plus de vingt ans à la musique en tant que pianiste de jazz avant de découvrir avec la photographie le mode d'expression qui lui correspond. Il débute en couvrant des concerts et des battles hip-hop puis se lance dans un projet artistique plus personnel : " InMotion - My life in movement ", ou comment magnifier l'expression corporelle en l'associant à une atmosphère et à un cadre architectural particuliers. Il concrétise ce dessein par la mise en scène de danseurs, gymnastes, circassiens ou sportifs dans des lieux atypiques, c'est-à-dire hors de leur contexte habituel. Ici dans des bibliothèques, françaises et étrangères, il établit une correspondance entre l'esprit des lieux et l'essence du mouvement des artistes. Jeux de formes, parallélisme des corps vivants et des lignes architecturales, clins d'œil poétiques, parfois humoristiques, composent cette sélection inspirée. 


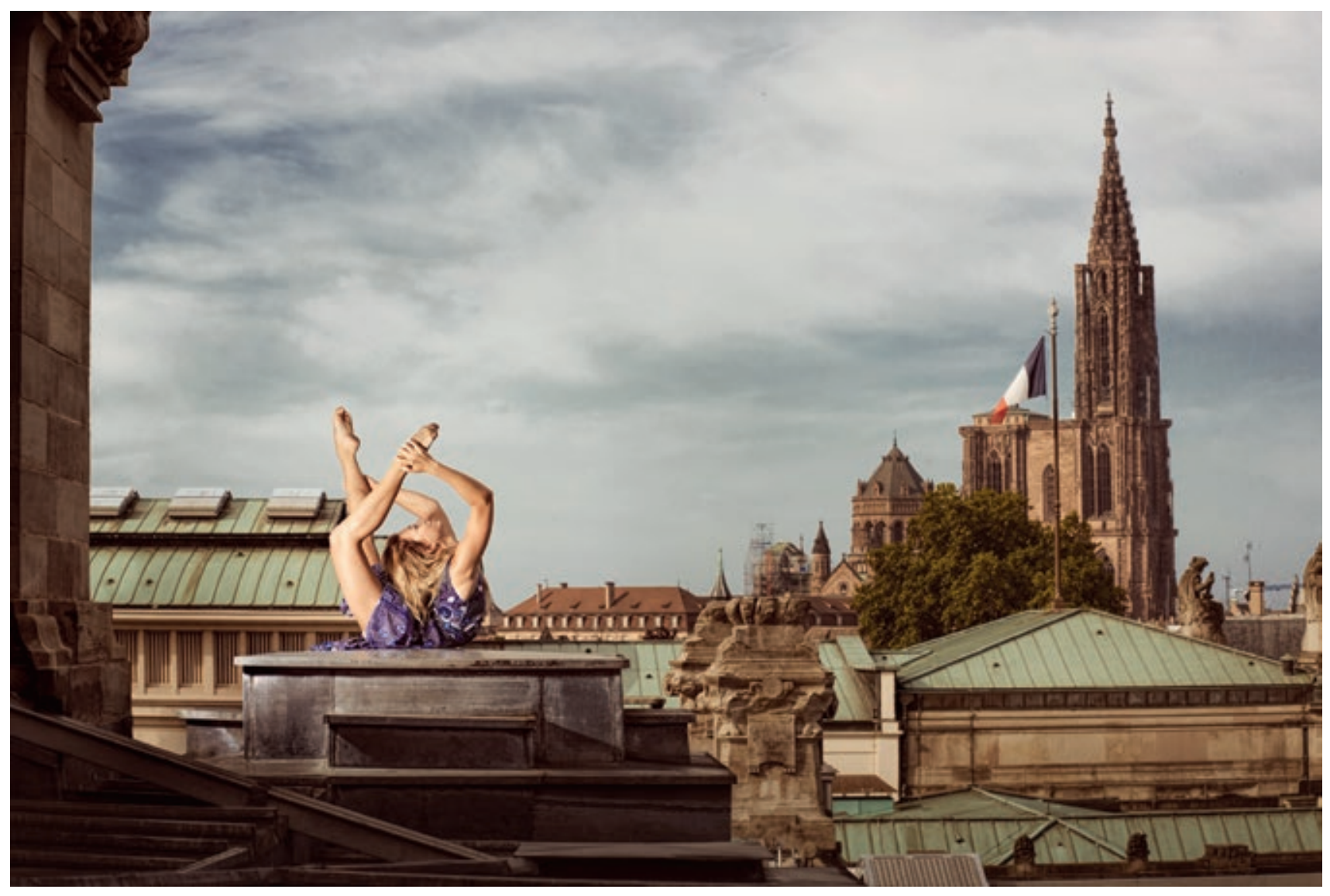




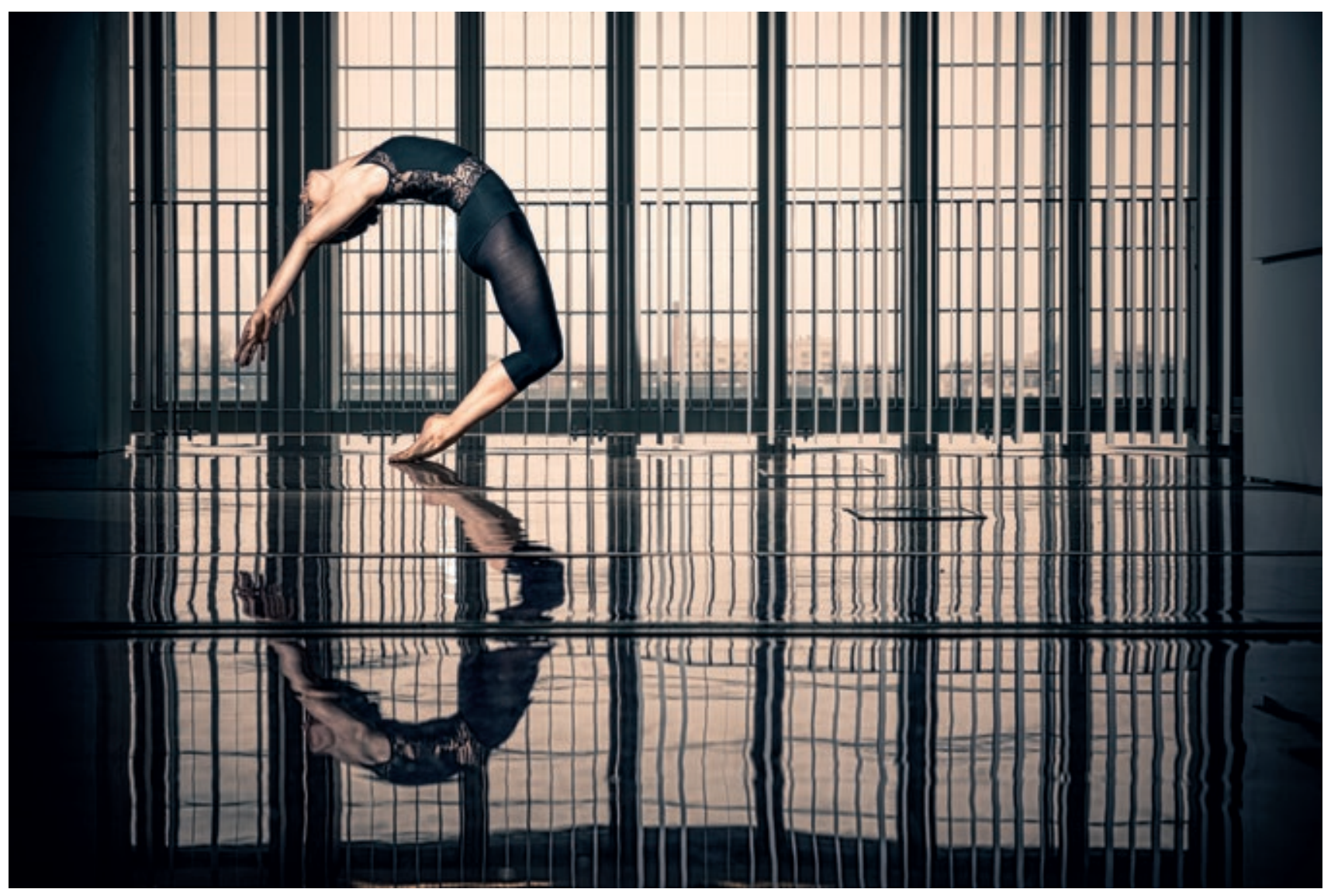

Fanny George

(Médiathèque André Malraux) 


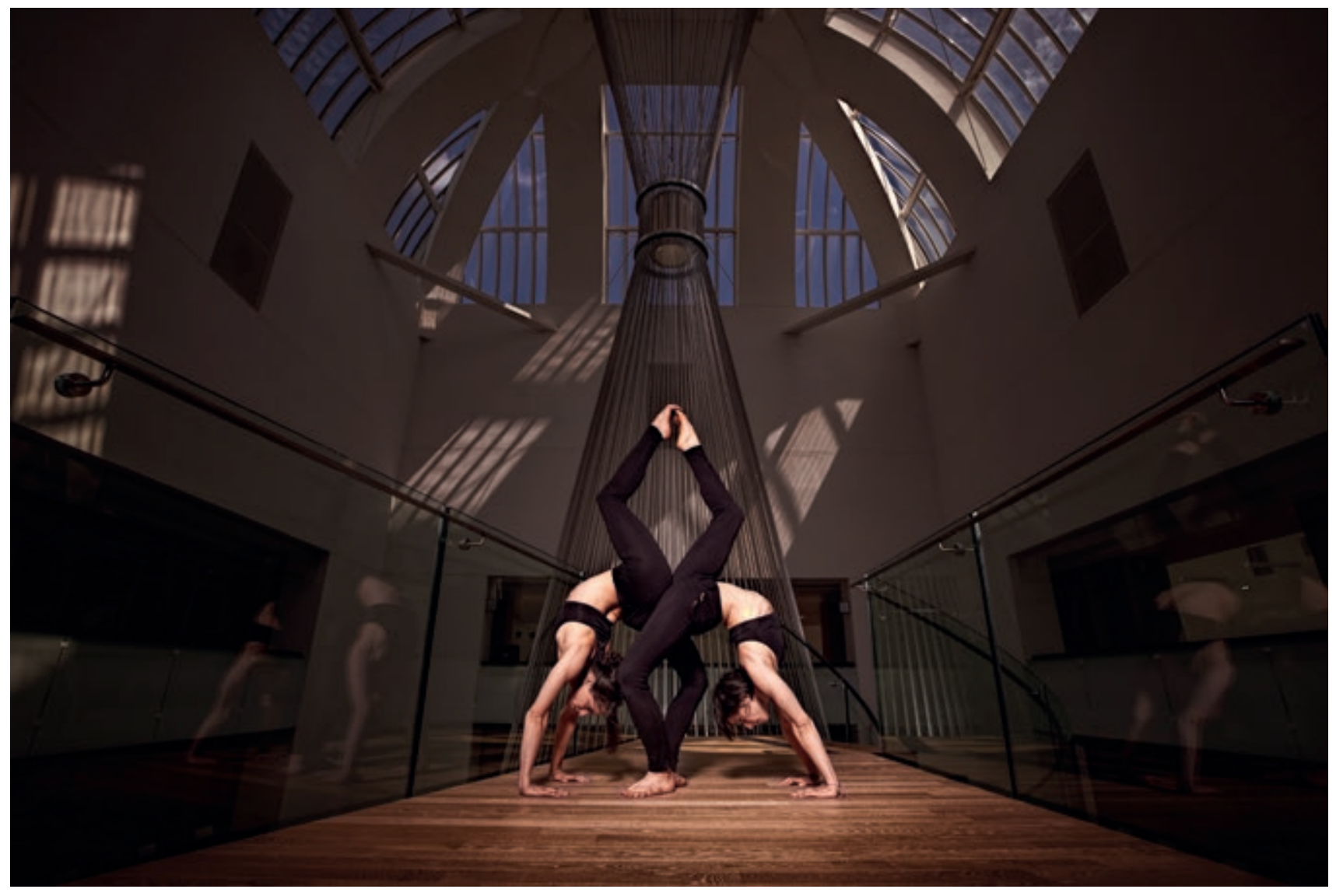

Fanny et Noémie George

(Bibliothèque nationale et universitaire de Strasbourg) 


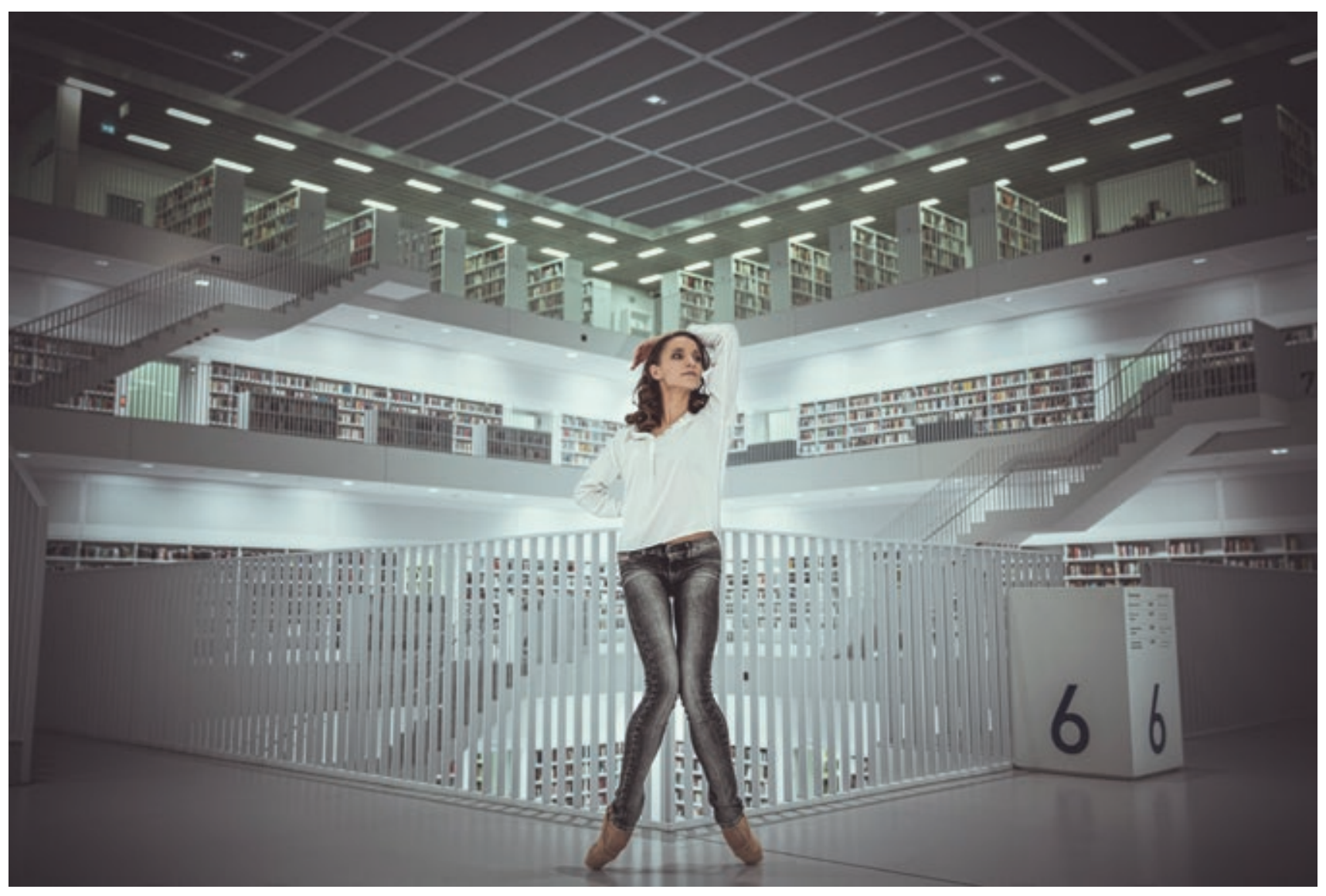

Miriam Kacerova

(Stadtbibliothek Stuttgart) 


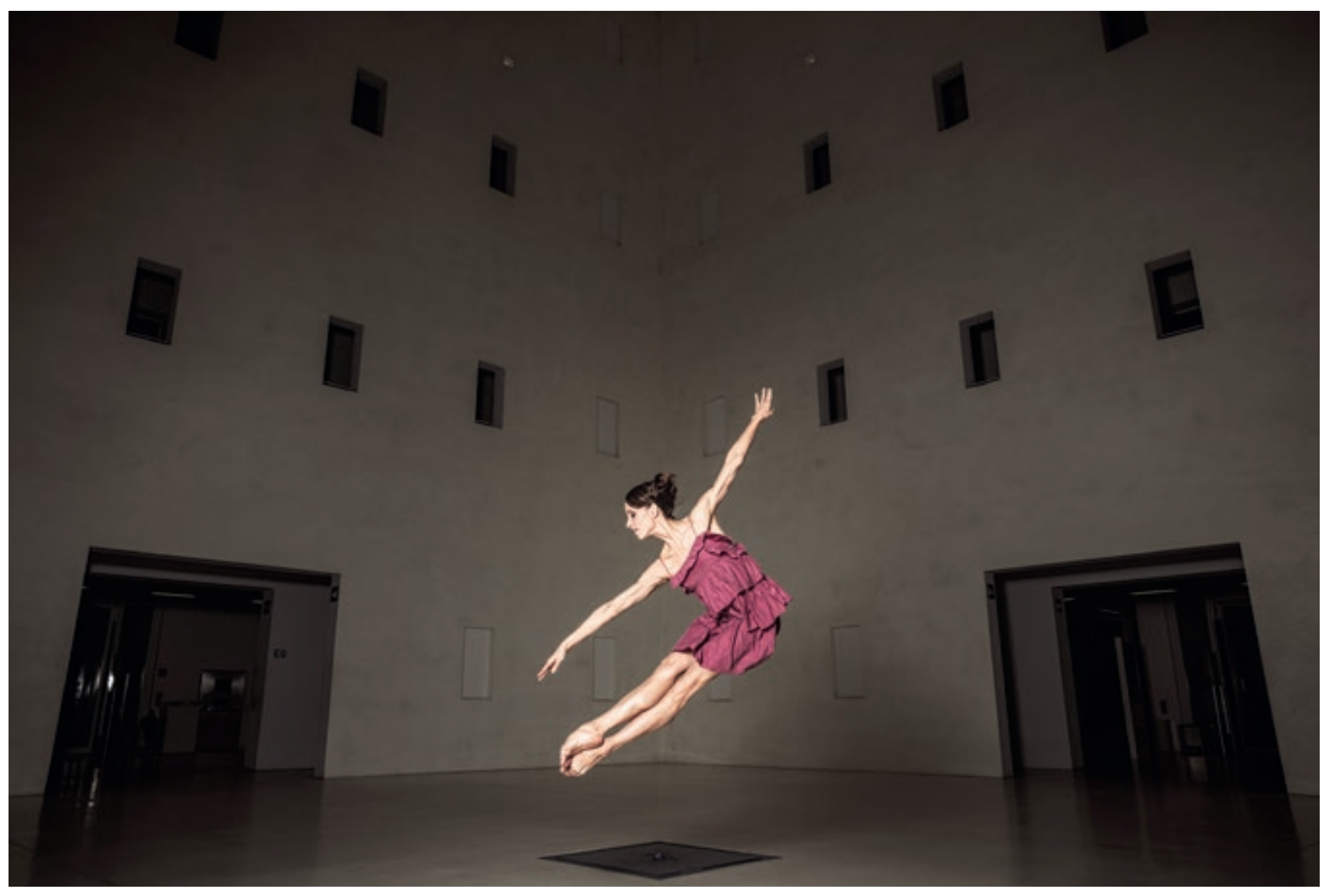

Miriam Kacerova

(Stadtbibliothek Stuttgart) 


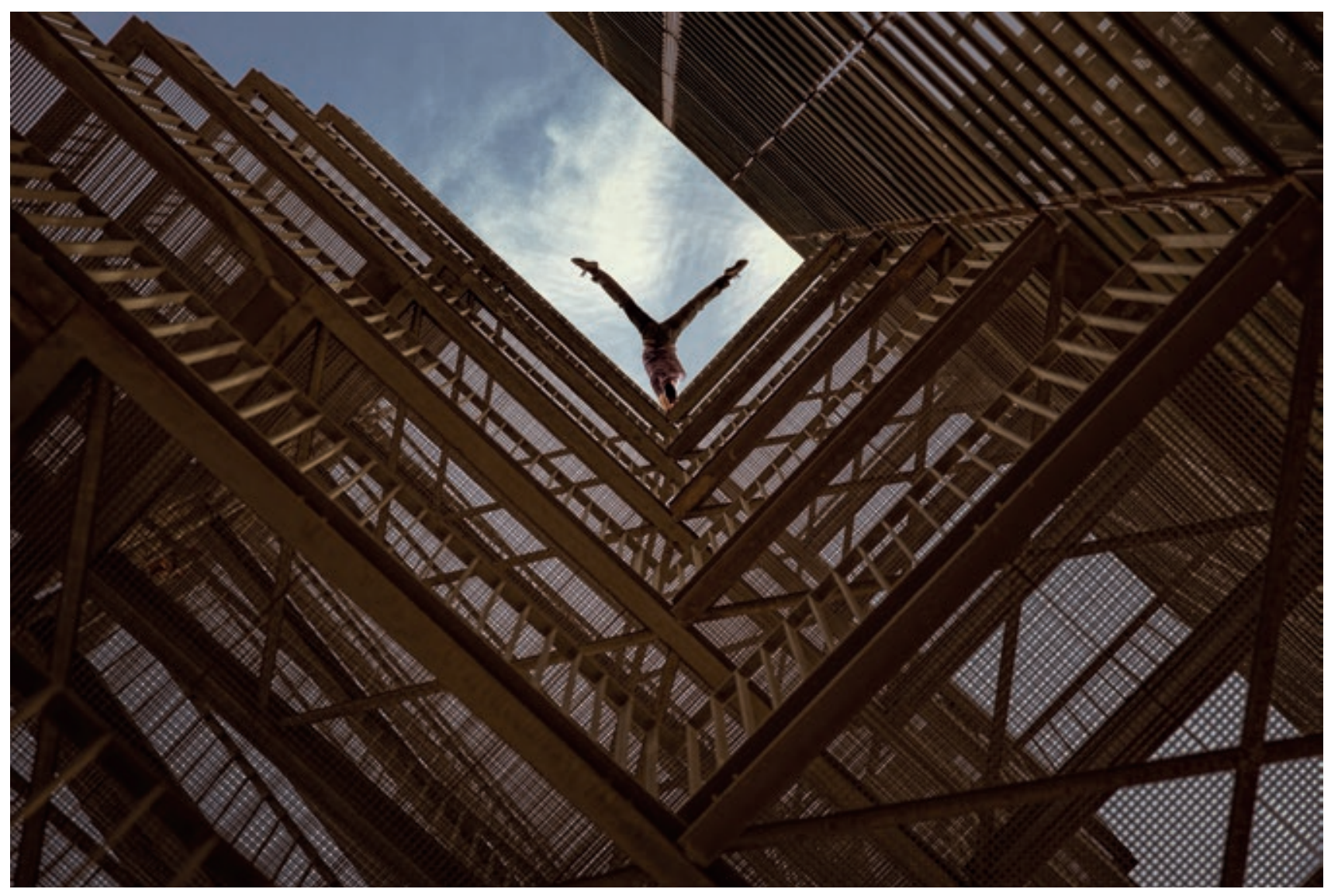

Nhật-Nam Lê

(Médiathèque André Malraux) 


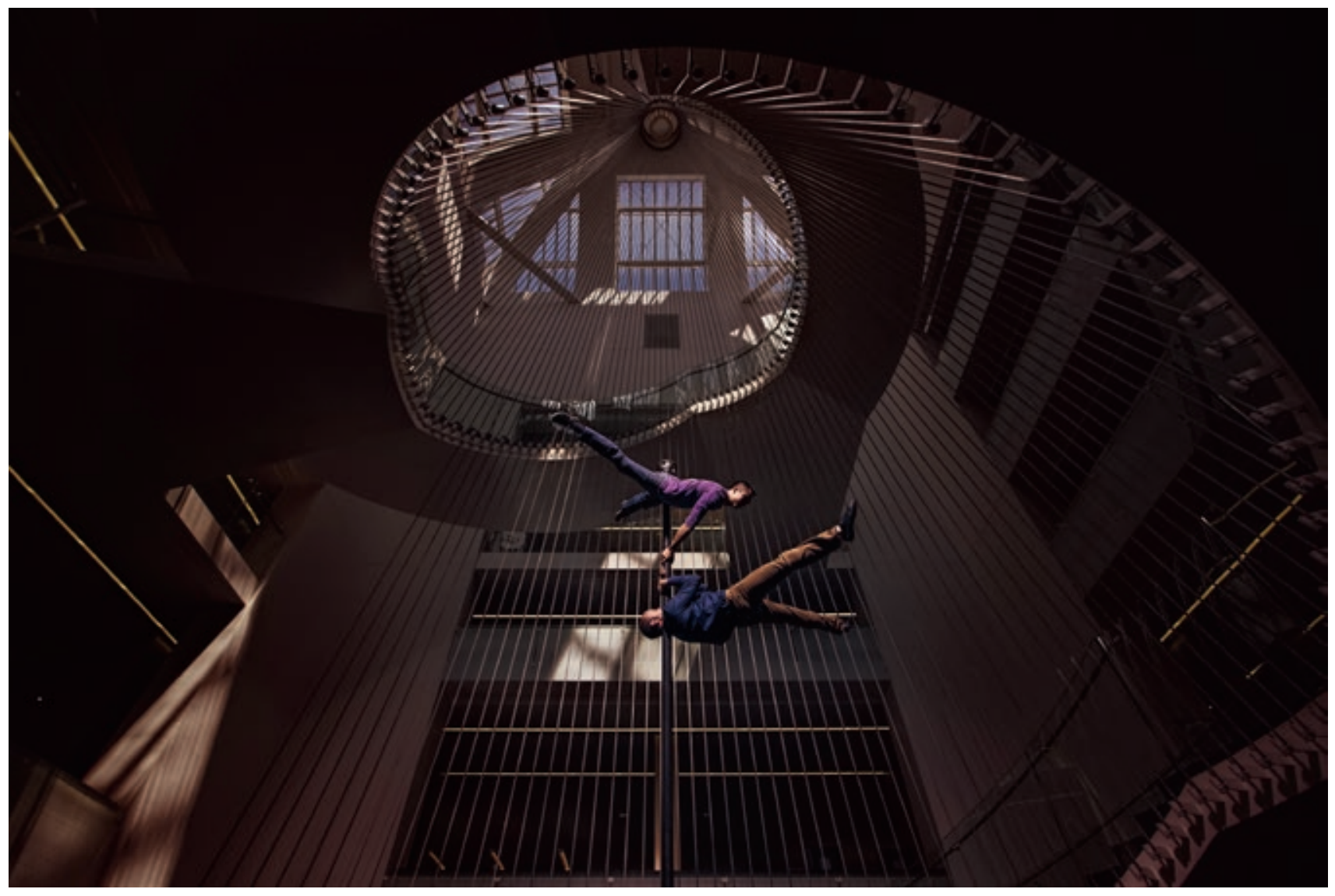

Nhật-Nam Lê et Paul Herzfeld

(Bibliothèque nationale et universitaire de Strasbourg) 


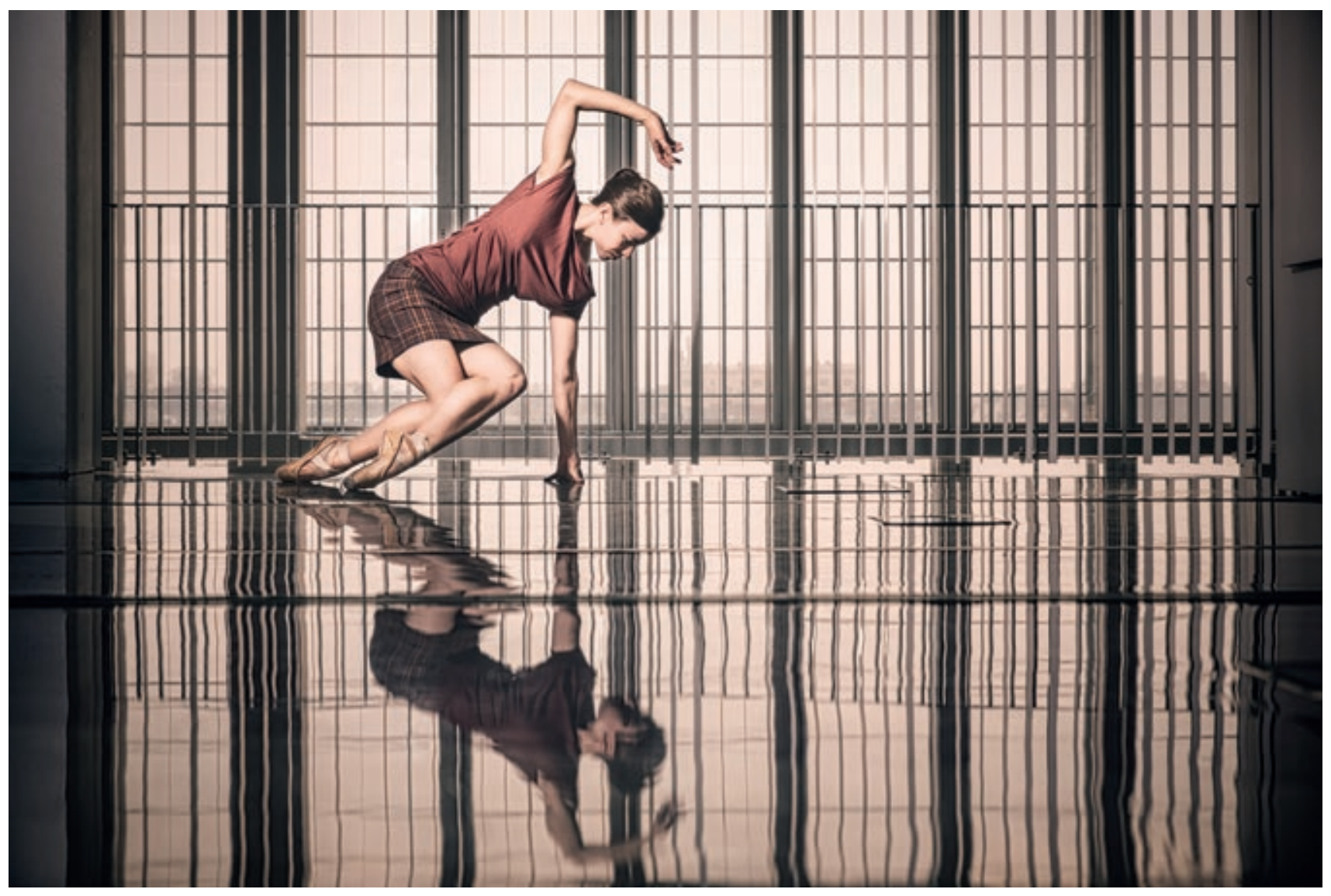

Sandra Ehrensperger

(Médiathèque André Malraux) 


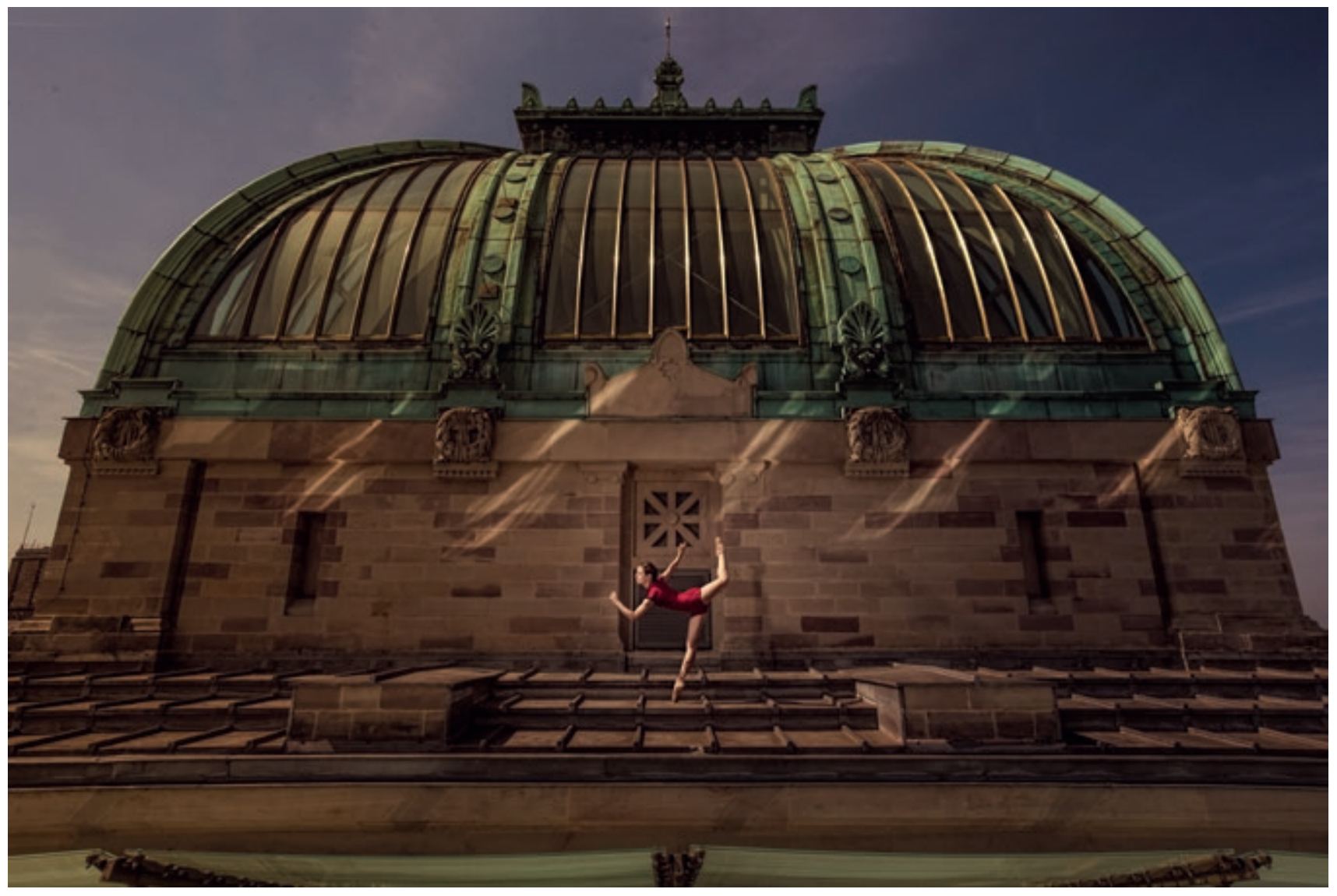

Sandra Ehrensperger

(Bibliothèque nationale et universitaire de Strasbourg) 


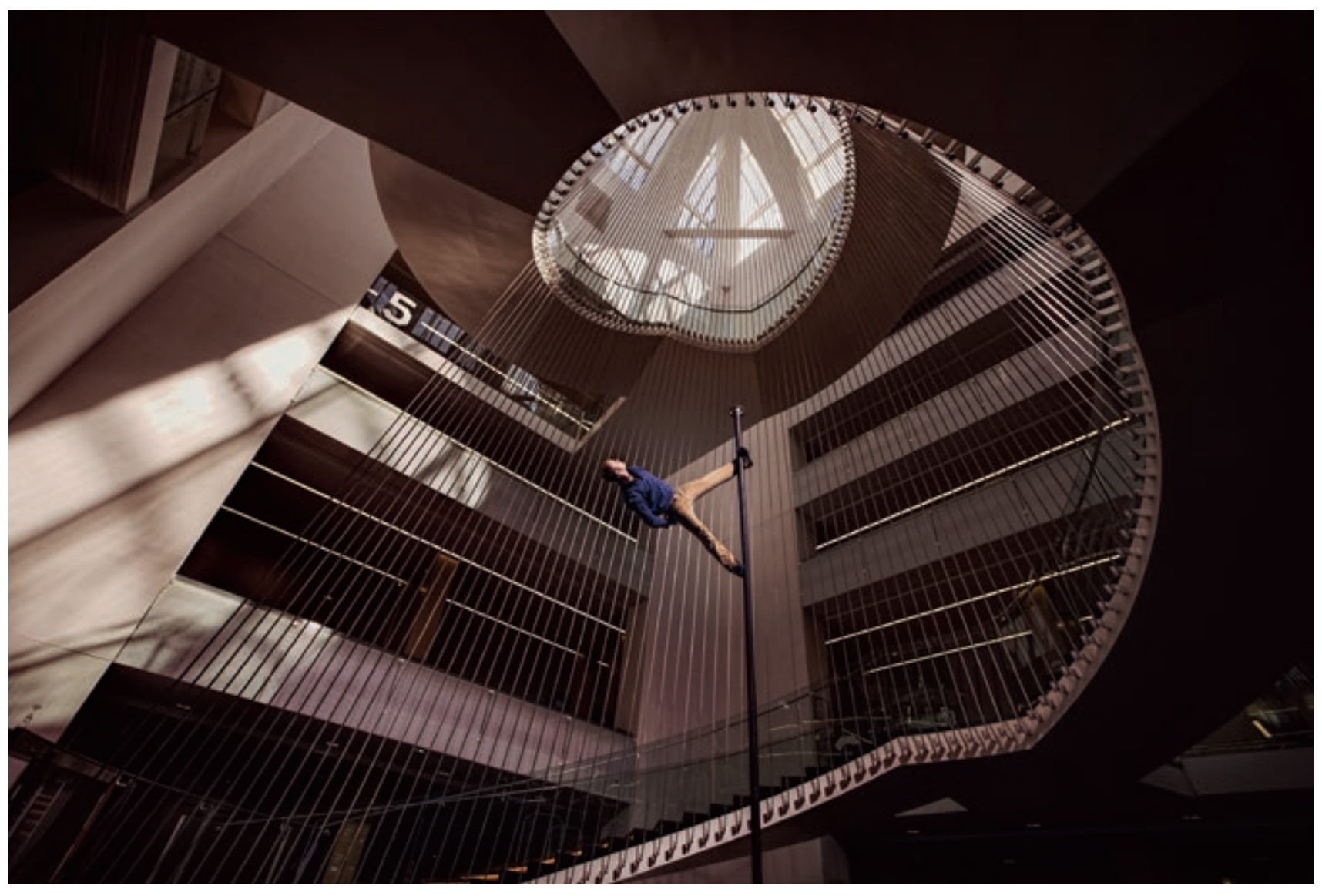

Paul Herzfeld

(Bibliothèque nationale et universitaire de Strasbourg) 


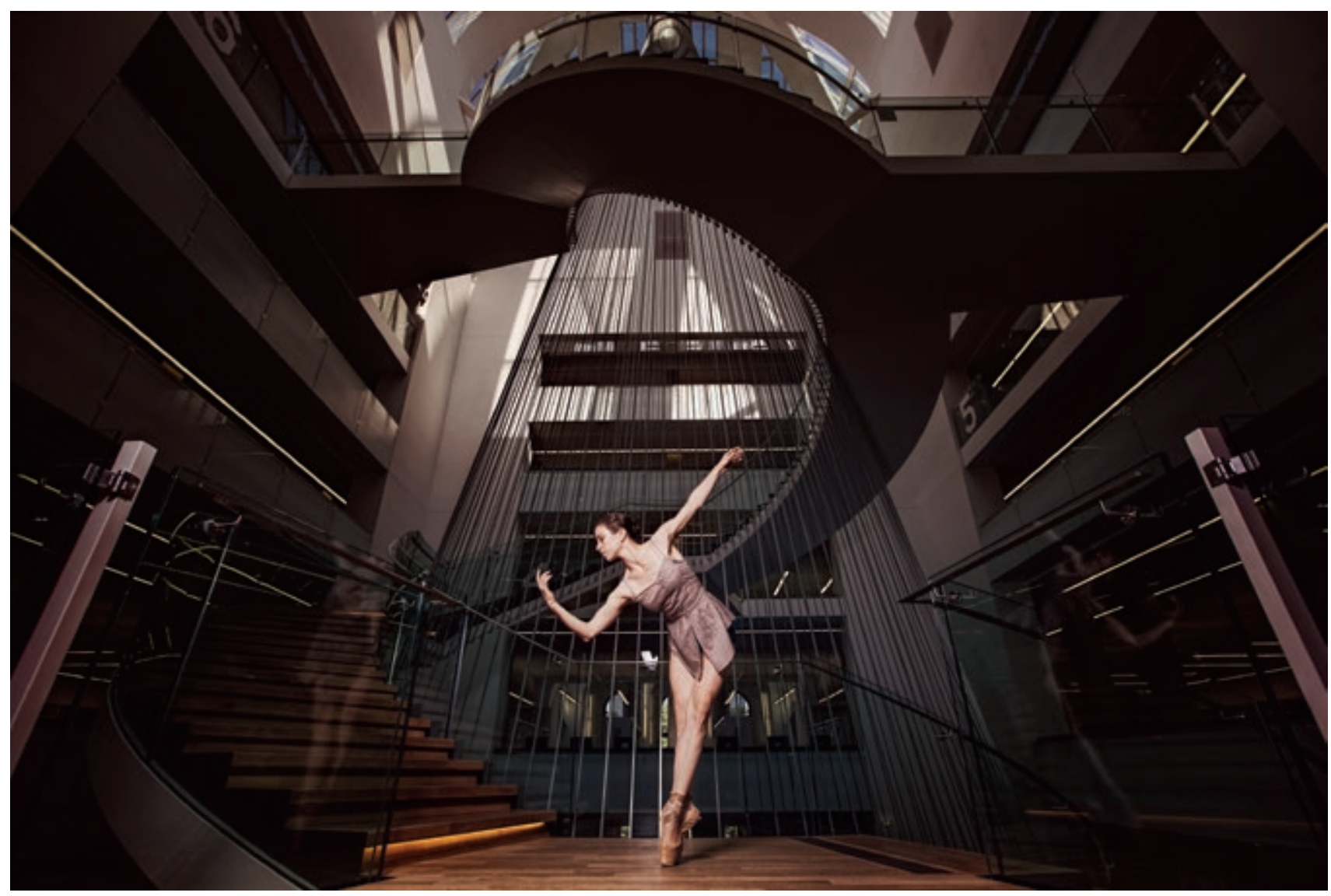

Sandra Ehrensperger

(Bibliothèque nationale et universitaire de Strasbourg) 